\title{
Pengembangan Aplikasi Sistem Kompetensi Dosen Dengan Menggunakan Program Hypertext Prepocessor (Php) Dalam Rangka Peningkatan Mutu Terhadap Kinerja Dan Hasil Pembelajaran
}

\author{
Teuku Fadjar Shadek ${ }^{1}$, Shodik Nuryadhin ${ }^{2}$ \\ Program Studi Teknik Informatika - STIKOM-Al Khairiyah \\ 1 fadjar_shadek@yahoo.com ${ }^{2}$ shodiknuryadhin@gmail.com
}

\begin{abstract}
Abstrak - Eksistensi dosen yang kompeten dan professional merupakan syarat mutlak hadirnya sistem dan praktik pendidikan yang berkualitas. Oleh karena itu, peningkatan kompetensi tenaga pendidik, yaitu salah satunya dosen, dibidang aplikasi teknologi informasi kompetensi atau yang sering diistilahkan dengan ICT (Information and Communication Technology) sangatlah penting. Kinerja dosen yang berkualitas sangat dibutuhkan oleh organisasi pendidikan. Indikator kinerja adalah ukuran kuantitatif dan/atau kualitatif yang menggambarkan tingkat pencapaian suatu sasaran atau tujuan yang telah ditetapkan. Terdapat beberapa faktor yang mampu mempengaruhi kinerja dosen diantaranya adalah kompetensi dosen. Penelitian ini dilakukan untuk menganalisa pengaruh kompetensi dosen Sekolah Tinggi Ilmu Komputer Al-Khairiyah terhadap kinerja dan hasil pembelajaran, sebagai pertimbangan dalam mengembangkan sistem kompetensi dosen. Hal-hal yang dipersiapkan adalah kesiapan Sekolah Tinggi Ilmu Komputer terhadap sistem kompetensi, menyiapkan jaringan infrastruktur sistem kompetensi, dari Hardware seperti Local Area Network, kemudian software dan brainware, serta hasil penilaian kompetensi menggunakan sistem kompetensi.
\end{abstract}

Kata Kunci : Kompetensi, Kinerja, Network.

\section{PENDAHULUAN}

Kualitas dosen memegang peranan penting di suatu perguruan tinggi. Seorang dosen dituntut untuk menguasai metode pembelajaran yang dilakukannya sehingga dapat memberikan nilai tambah bagi mahasiswa didiknya. Metode pembelajaran yang tepat pada saat mengajar akan menghasilkan hasil belajar yang lebih baik. Untuk mencapai tujuan proses belajar mengajar yang menghasilkan lulusan berkualitas, maka diperlukan peningkatan mutu dalam penyelenggaraan pendidikan.

Mengingat pentingnya peranan dosen dalam proses menciptakan sumber daya manusia yang berkualitas, maka dosen yang mengajar harus memiliki persyaratan yang telah ditentukan oleh undang-undang. Berdasarkan Undang-Undang Nomor 14 Tahun 2005 tentang guru dan dosen, menyatakan bahwa dosen memiliki kualifikasi akademik, kompetensi, sertifikat pendidik, sehat jasmani dan rohani dan memenuhi kualifikasi lain yang bersyaratkan satuan pendidikan tinggi tempat bertugas, serta memiliki kemampuan untuk mewujudkan tujuan pendidikan nasional.

Berdasarkan pengertian tersebut, maka dosen memiliki peranan yang sangat penting dalam proses pendidikan. Kualitas dosen akan mempengaruhi kinerjanya dalam memberikan ilmu pengetahuan kepada peserta didiknya. Oleh karena itu, penting sekali untuk dosen mengetahui kompetensi yang dimilikinya sehingga dosen dapat mengevaluasi kekurangannya dan terus memperbaiki kompetensi yang dimilikinya untuk meningkatkan kemampuan mengajar yang dimilikinya. Untuk mengetahui kompetensi yang dimiliki setiap dosen dibutuhkan sistem content management system $(C M S)$. Sistem ini akan melakukan perubahan dari sistem kompetensi konvensional menjadi berbasis program hypertext prepocessor (PHP), dimana dosen dapat melihat kompetensinya seperti pengetahuan, keterampilan, perilaku, jumlah SKS yang sudah diberikan, pelatihan, penelitian dan sebagainya

Adapun langkah-langkah pengembangan sistem kompetensi berbasis multimedia untuk Sekolah Tinggi Ilmu Komputer adalah sebagai berikut: melakukan analisis kebutuhan data, analisis kebutuhan proses, analisa kebutuhan software dan hardware, analisis kebutuhan pengguna, melakukan perancangan model bisnis, perancangan sistem, implentasi sistem dengan cara melakukan analisis pre-test dan post-test untuk mencari tanggapan mahasiswa terhadap kompetensi dosen tersebut.

\subsection{Identifikasi Masalah}

Berdasarkan identifikasi masalah adalah sebagai berikut ini :

a) Pengaruh motivasi kerja terhadap kinerja dosen.

b) Keaktifan dosen terhadap kompetensi dosen.

\subsection{Perumusan Masalah}

Bagaimana aplikasi moodle dapat dikembangkan untuk sistem kompetensi dosen berbasis web untuk sekolah tinggi ilmu komputer? 


\section{DASAR TEORI}

\subsection{Sistem Informasi}

Sistem merupakan elemen yang saling berhubungan sama sama lain yang membentuk satu kesatuan dalam

usaha mencapai suatu tujuan. (Budi, 2002:168).

Sedangkan informasi adalah data yang diolah menjadi bentuk yang lebih berguna dan lebih berarti bagi yang menerimanya. Jogiyanto HM (2005:8).

Maka, sistem informasi adalah suatu sistem didalam suatu organisasi yang mempertemukan kebutuhan pengolahan tansaksi harian, mendukung operasi bersifat manajerial dan kegiatan strategi dari suatu organisasi dan menyediakan pihak luar tertentu dengan laporanlaporan yang diperlukan. (Jogiyanto, 2005:11).

Definisi sistem informasi juga dikemukakan oleh Aziz (2006) bahwa sistem informasi adalah suatu sistem yang dibuat oleh manusia yang terdiri dari komponenkomponen dalam organisasi untuk mencapai suatu tujuan yaitu menyajikan informasi, dan komponen system informasi meliputi hardware, software, manusia, data dan prosedur.

Terdapat beberapa komponen-komponen sistem informasi yaitu sebagai berikut:

1. Blok masukan (input block). Terdiri dari semua jenis data baik berupa teks, suara dan pendapat masukan dari sistem informasi serta metode media yang dilibatkan.

2. Blok Model (Model Block). Terdiri dari kombinasi prosedur, logika dan model matematika yang akan memanipulasi data input maupun data yang tersimpan di basis data dengan cara tertentu agar menghasilkan output yang diinginkan. Didalam sistem analisis desain, model blok digunakan untuk spesifikasi dokumen seperti tabel keputusan, data flow diagram, struktur analisis dan teknik pendesain dan lain-lain.

3. Blok Keluaran (output block). Merupakan produk dari sistem informasi yang akan menentukan kualitas informasi serta dokumen yang berguna untuk semua tingkatan manajemen serta semua pengguna sistem.

4. Blok Teknologi (Technologi Block). Merupakan kontak alat (toolbox) dalam sistem informasi yang mencakup input, model penyimpanan dan akses data serta output yang membantu pengendalian sistem dimana teknologi mempunyai tiga unsur, yaitu:

a. Brainware (Unsur manusia).

b. Software (perangkat lunak).

c. Hardware (perangkat keras).

5. Blok Basis Data (Database Block). Merupakan kumpulan data yang saling berhubungan satu dengan yang lainnya, tersimpan diperangkat keras komputer dan perangkat lunak untuk memanipulasinya. Data perlu disimpan dalam basis data untuk keperluan penyediaan informasi lebih lanjut. Data didalam basis data perlu diorganisasikan sedemikian rupa agar informasi yang dihasilkan berkualitas.

6. Blok Kendali (control Block). Berfungsi untuk mengendalikan sistem agar terhidar dari hal-hal yang dapat merusak sistem sehingga presentasi kesalahan yang terjadi dapat ditekan sekecil mungkin.

\subsection{Kompetensi}

Penelitian Trianto dan Tuti pada tahun 2006 mendefinisikan bahwa Undang-Undang Republik Indonesia Nomor 14 tahun 2005 tentang guru dan dosen pasal 1 ayat (2) mendefinisikan bahwa dosen adalah pendidik professional dan ilmuan dengan tugas utama mentransformasikan, mengembangkan dan menyebar luaskan ilmu pengetahuan teknologi dan seni melalui pendidik, penelitian dan pengabdian kepada masyarakat (Undang - Undang Republik Indonesia No. 14 Tahun 2005 tentang Guru dan Dosen). Berdasarkan pengertian tersebut, maka dosen memiliki peranan yang sangat penting sebagai ujung tombak pelaksana keseluruhan proses pendidikan. Dosen bertanggung jawab terhadap proses belajar mengajar, oleh karena itu dalam upaya meningkatan mutu pendidikan tinggi dosen memegang peranan dan kedudukan kunci dalam keseluruhan proses pendidikan terutama di perguruan tinggi.

Penelitian Arwildayanto pada tahun 2012 mendefinisikan bahwa dosen adalah salah satu komponen utama dalam sistem pendidikan di perguruan tinggi. Peran, tugas dan tanggung jawab dosen sangat penting dalam mewujudkan pendidikan nasional, yaitu mencerdaskan kehidupan bangsa, meningkatkan kualitas manusia Indonesia, meliputi kwalitas iman dan takwa, akhlak mulia, dan penguasaanvilmu pengetahuan, teknologi, dan seni, serta mewujudkan masyarakat Indonesia yangvmaju, adil, makmur, dan beradab. Untuk melaksanakan fungsi, peran dan kedudukan yang sangat strategis tersebut diperlukan dosen yang professional. Konsepsi manajemen SDM perguruan tinggi memberikan pemahaman bahwa Sumber daya manusia dosen (SDMD), memiliki posisi yang vital dalam membentuk image mutu lulusan maupun mutu perguruan tinggi secara umum. Posisi ini diperkuat Manajemen Sumber Daya Manusia Perguruan Tinggi dengan fakta bahwa, dosen memiliki otoritas tinggi dalam proses akademik, dan malahan lebih tinggi dari profesi serupa di lembaga pendidikan di bawahnya.

Penelitian Roger Pressman pada tahun 2005 mendefinisikan Menurut Roger Pressman (2005) : Sistems Development Life Cycle (Siklus Hidup Pengembangan Sistem) dalam rekayasa perangkat lunak adalah proses pembuatan dan pengubahan sistem serta model dan metodologi yang digunakan untuk mengembangkan sistem tersebut. Konsep ini umumnya merujuk pada sistem komputer atau sistem informasi. SDLC juga merupakan pola yang diambil untuk mengembangkan sistem perangkat lunak, yang terdiri dari beberapa tahap yaitu: analisa (analysis), desain 
(design), implementasi (implementation), uji coba (testing) dan pengelolaan (maintenance).

Dari definisi di atas dapat di simpulkan bahwa sistem atau konsep pendidikan yang memanfaatkan teknologi informasi dalam proses belajar mengajar dapat disebut sebagai suatu kompetensi dosen. Disimpulkan juga bahwa kompetensi dosen adalah sebuah proses kinerja dosen yang berbasis elektronik dengan salah satu media yang digunakan adalah jaringan komputer yang memungkinkan untuk dikembangkan dalam bentuk berbasis web, sehingga kemudian dikembangkan ke jaringan komputer yang lebih luas yaitu internet. Penyajian kompetensi dosen berbasis web ini bisa menjadi lebih interaktif dalam penelitian ini disebut kompetensi dosen berbasis web.

\subsection{Pengertian Web}

Website adalah suatu media publikasi elektronik yang terdiri dari halaman-halaman web (web page) yang terhubung satu dengan yang lain menggunakan Link yang dilekatkan pada suatu teks atau image. Website dibuat pertama kali oleh Tim Barners Lee pada tahun 1990. Website dibangun dengan menggunakan bahasa Hypertext Markup Language (HTML) dan memanfaatkan protokol komunikasi Hypertext Transfer Protocol (HTTP) yang terletak pada application layer pada referensi layer OSI. Halaman website diakses menggunakan aplikasi yang disebut internet browser (Kadir, 2004).

Menurut (Jasmadi,2004), fungsi dari website adalah :

1. Fungsi Komunikasi

Website berfungsi sebagai media komunikasi antara pembuat/pemilik dengan pengunjung atau pengunjung dengan pengunjung lain. Komunikasi dilakukan dengan menggunakan aplikasi web messanger, web forum, web chat, web mail, dan lain sebagainya.

2. Fungsi Informasi

Website berfungsi untuk menyediakan informasi bagi pengunjung.

3. Fungsi Hiburan

Website menjadi sarana hiburan, menyediakan layanan online game, video streaming, music streaming, dan lain sebagainya.

4. Fungsi Transaksi

Website berfungsi sebagai sarana untuk melaksanakan transaksi bisnis seperti : online order, pembayaran menggunakan kartu kredit, pembayaran dengan e-gold, dan sebagainya.

5. Fungsi Pendidikan

Website berfungsi sebagai sarana dalam interaksi guru dan siswa sehingga tidak terikat oleh jarak dan waktu.

\subsection{Unified Modeling Language (UML)}

UML adalah salah satu standar bahasa yang banyak digunakan di dunia industri untuk mendefinisikan requirement, membuat analisis dan desain, serta menggambarkan arsitektur dalam pemrograman berorientasi objek. Dengan kata lain UML berarti bahasa pemodelan standar dan merupakan alat komunikasi yang konsisten dalam mensuport para pengembang saat ini[8].

Dari kedua pendapat tersebut, dapat disimpulkan bahwa UML adalah bahasa pemodelan sistem yang digunakan sebagai alat komunikasi antara pengembang dengan pengguna atau antar pengembang itu sendiri untuk pemrograman berorientasi objek (Object Oriented Programming).

\section{TEKNIK PENGUMPULAN DATA}

Dalam membangun sistem informasi ini terlebih dahulu dilakukan pengumpulan data yaitu :

a. Penelitian Lapangan ( field research) . Pada tahap awal dalam penelitian ini dikumpulkan data terlebih dahulu dengan studi lapangan di komplek kampus Al - Khairiyah yang berlokasi J1. H. Enggus Arja No. 1 Citangkil, Cilegon - Banten.

b. Penelitian Kepustakaan (Library Research). Pada tahap ini dilakukan pengumpulan data dengan mempelajari buku-buku (literature) mengenai sistem informasi berbasis bahasa pemrgoraman PHP dan langkah-langkah membangun aplikasi berbasis web.

\subsection{Aplikasi}

Aplikasi adalah sebuah media penunjang dalam sebuah object yang memiliki beberapa instruksi yang disusun sedemikian rupa sehingga dapat menghasilkan input dan output. Pendapat lain mengatakan bahwa Aplikasi adalah penerapan dari rancang sistem untuk mengolah data yang menggunakan aturan atau ketentuan bahasa pemrograman tertentu. Aplikasi adalah suatu program komputer yang dibuat untuk mengerjakan dan melaksanakan tugas khusus dari pengguna.

\subsection{Informasi}

Informasi adalah data yang telah dirposes/diolah ke dalam bentuk yang sangat berarti untuk penerimanya dan merupakan nilai yang sesungguhnya atau dipahami dalam tindakan atau keputusan yang sekarang atau nantinya. Pada literatur yang lain dikatakan bahwa Informasi adalah data yang sudah diolah menjadi sebuah bentuk yang berarti bagi pengguna, yang bermanfaat dalam pengambilan keputusan saat ini atau mendukung sumber informasi.

\subsection{Web}

Web atau website merupakan bahasa suatu aplikasi yang berjalan pada server dan dapat diakses melalui jaringan internet secara world wide. Website menawarkan berbagai macam keutungan dalam pemanfaatannya, antara lain :

1. Mudah untuk diakses,

2. Dapat diakses dari dosen dari mana saja dan kapan saja.

\section{ANALISA KEBUTUHAN}

Pada pembangunan aplikasi ini dibutuhkan spesifikasi minimal hardware sebagai berikut : 
TABEL 1 KEBUTUHAN HARDWARE

\begin{tabular}{|c|c|c|c|}
\hline No & $\begin{array}{c}\text { Nama } \\
\text { Hardware }\end{array}$ & Spesifikasi & Jml \\
\hline 1 & Laptop & Processor : Intel Core & 1 \\
& Lenovo & I3 1.8 Ghz & \\
& & Ram $: \mathbf{2}$ GB & \\
\hline 2 & Printer & Hardisk $: \mathbf{5 0 0}$ GB & \\
\hline
\end{tabular}

Software yang digunakan untuk pembangunan aplikasi sebagai berikut :

TABEL 2 KEBUTUHAN SOFTWARE

\begin{tabular}{|c|c|c|c|}
\hline No & $\begin{array}{c}\text { Kebutu } \\
\text { han }\end{array}$ & Keterangan & Fungsi \\
\hline 1 & $\begin{array}{l}\text { Sistem } \\
\text { Operasi }\end{array}$ & $\begin{array}{l}\text { Windows } 7 \\
\text { home basic }\end{array}$ & $\begin{array}{l}\text { Sebagai Sistem Operasi } \\
\text { yang dipakai untuk } \\
\text { menjalankan Software }\end{array}$ \\
\hline \multirow{7}{*}{2} & \multirow{7}{*}{ Aplikasi } & ХАМРP & $\begin{array}{l}\text { Kebutuhan Web } \\
\text { Server (apache, mysql } \\
\text { dan php) }\end{array}$ \\
\hline & & Swish MX & Text Editor \\
\hline & & $\begin{array}{c}\text { Adobe } \\
\text { Photoshop } \\
\text { CS.3 }\end{array}$ & Image Editor \\
\hline & & $\begin{array}{c}\text { Mozila } \\
\text { Firefox } 45\end{array}$ & $\begin{array}{l}\text { Aplikasi untuk } \\
\text { menjalankan web }\end{array}$ \\
\hline & & PHP & $\begin{array}{l}\text { Aplikasi yang } \\
\text { digunakan untuk } \\
\text { pembuatan } \\
\text { kompetensi dosen }\end{array}$ \\
\hline & & $\begin{array}{c}\text { Power } \\
\text { Point } 2007\end{array}$ & $\begin{array}{l}\text { Aplikasi yang } \\
\text { digunakan buat } \\
\text { persentasi }\end{array}$ \\
\hline & & $\begin{array}{l}\text { Flash } \\
\text { Player }\end{array}$ & $\begin{array}{l}\text { Aplikasi yang } \\
\text { digunakan untuk } \\
\text { menjalakan animasi } \\
\text { flash }\end{array}$ \\
\hline
\end{tabular}

\section{ANALISA PENGGUNA}

Pengguna dapat mengakses aplikasi dengan menggunakan aplikasi browser ke alamat IP komputer server yang sudah diberikan. Pengguna aplikasi dapat dibedakan menjadi 3 pengguna, yaitu ;

1. Admin E-Learning dapat mengakses aplikasi ini melalui alamat IP komputer server. admin mendapatkan masing-masing username dan password untuk dapat mengakses aplikasi. Admin yang sudah bisa masuk ke aplikasi dapat mengelola data data aplikasi untuk kebutuhan dosen dan mahasiswa.
2. Dosen pengguna yang dapat melakukan seluruh fungsi course termasuk menambah aktivitas seperti upload matakuliah, tugas, quis dan memberi nilai.

3. Mahasiswa pengguna yang mempunyai hak akses mendownload matakuliah, mengikuti tugas, dan mengikuti quis http://akademik.stikom-alkhairiyah.ac.id..

\section{ANALISA DATA}

Dalam membangun e-learning berbasis web untuk sekolah tinggi ilmu komputer tentu harus dianalisa kebutuhan data apa saja yang diperlukan atau dibutuhkan. Tujuannya adalah untuk mempermudah dan menjaga konsistensi perangkat lunak yang akan dibuat. Berikut analisa kebutuhan yang diperlukan dalam pembuatan kompetensi berbasis web untuk sekolah tinggi ilmu komputer.

\section{PERANCANGAN}

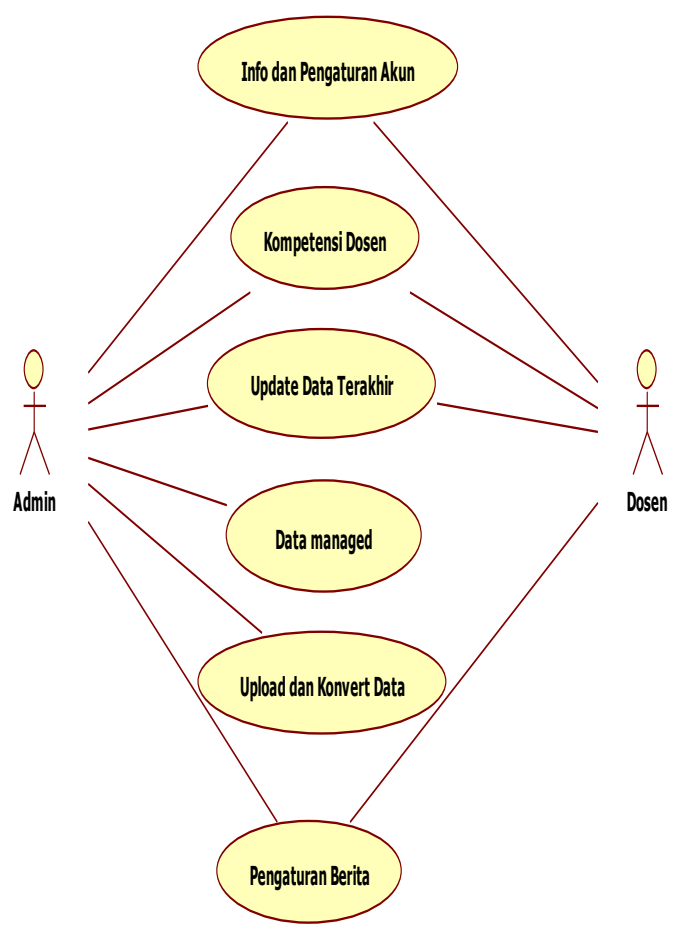

Gambar 1 Diagram Use Case

Aliran logika pada use case di atas terdiri flow of event download, flow of event upload dan flow of event managed. Rincian tabel flow of event seperti tabel dibawah ini : 


\begin{tabular}{|c|c|c|c|}
\hline $\begin{array}{l}\text { Nama of Use } \\
\text { Case }\end{array}$ & \multicolumn{3}{|c|}{ Akses Download } \\
\hline Tujuan & \multicolumn{3}{|c|}{ User dapat melihat web kompetensi } \\
\hline Prasyarat & \multicolumn{3}{|c|}{ kompetensi bisa dilihat oleh dosen } \\
\hline $\begin{array}{l}\text { Kondisi } \\
\text { Akhir Suskses }\end{array}$ & \multicolumn{3}{|c|}{$\begin{array}{l}\text { Tampil list kompetensi dosen dalam } \\
\text { bentuk tabel }\end{array}$} \\
\hline $\begin{array}{l}\text { Kondisi } \\
\text { Gagal }\end{array}$ & \multicolumn{3}{|c|}{ Blank arau belum diinput } \\
\hline Aktor Utama & \multicolumn{3}{|l|}{ Dosen } \\
\hline $\begin{array}{l}\text { Aktor } \\
\text { Sekunder }\end{array}$ & \multicolumn{3}{|l|}{ - } \\
\hline Pemicu & \multicolumn{3}{|c|}{$\begin{array}{l}\text { User mengakses alamat URL dan } \\
\text { memilih menu kompetensi }\end{array}$} \\
\hline \multirow[t]{3}{*}{ Alur Utama } & Langkah & Aktor & Sistem \\
\hline & 1 & Login & $\begin{array}{l}\text { Menampilk } \\
\text { an beranda }\end{array}$ \\
\hline & 2 & $\begin{array}{l}\text { Memilih } \\
\text { menu } \\
\text { kompetensi }\end{array}$ & $\begin{array}{l}\text { Menampilk } \\
\text { an menu } \\
\text { kompetensi }\end{array}$ \\
\hline
\end{tabular}

\begin{tabular}{|c|c|c|c|}
\hline Tujuan & \multicolumn{3}{|c|}{$\begin{array}{l}\text { Untuk memngelola kompetensi } \\
\text { (tambah, Simpen, Edit, Hapus, Cari) }\end{array}$} \\
\hline Prasyarat & \multicolumn{3}{|c|}{$\begin{array}{l}\text { Punya akses ke dalam aplikasi } \\
\text { memlalui login }\end{array}$} \\
\hline $\begin{array}{l}\text { Kondisi } \\
\text { Akhir Suskses }\end{array}$ & \multicolumn{3}{|c|}{$\begin{array}{l}\text { Bisa menambahkan, edit dan hapus } \\
\text { serta dapat melakukan sort data dan } \\
\text { filter }\end{array}$} \\
\hline $\begin{array}{l}\text { Kondisi } \\
\text { Gagal }\end{array}$ & \multicolumn{3}{|c|}{$\begin{array}{l}\text { Tidak bisa menambahkan edit \& } \\
\text { hapus }\end{array}$} \\
\hline Aktor Utama & \multicolumn{3}{|c|}{ Admin } \\
\hline $\begin{array}{l}\text { Aktor } \\
\text { Sekunder }\end{array}$ & \multicolumn{3}{|l|}{-} \\
\hline Pemicu & \multicolumn{3}{|c|}{$\begin{array}{l}\text { Dosen mengakses alamat URL dan } \\
\text { memilih menu matakuliah }\end{array}$} \\
\hline \multirow[t]{3}{*}{ Alur Utama } & Langkah & Aktor & Sistem \\
\hline & 1 & Login & $\begin{array}{l}\text { Menampilk } \\
\text { an beranda }\end{array}$ \\
\hline & 2 & $\begin{array}{l}\text { Klik menu } \\
\text { kompetensi }\end{array}$ & $\begin{array}{l}\text { Menampilk } \\
\text { an data } \\
\text { kompetensi } \\
\text { dan } \\
\text { filternya }\end{array}$ \\
\hline
\end{tabular}

\section{HASIL DAN PEMBAHASAM}

Sistem informasi kompetensi sekolah tinggi ilmu komputer dibuat untuk kalangan civitas kampus dan untuk dosen, cara menggunakan tinggal login yang sudah di daftarkan oleh admin kemudian mengakses aplikasi browser web firefox, crome dan lain-lain, dengan mengakses url : http://kompetensi.stikomalkhairiyah.ac.id dan memalui ip komputer server dari jaringan lokal. User dapat dengan mudah menggunakan untuk kepentingan masing-masing.

Berikut ini fasilitas-fasilitas yang disediakan pada sistem informasi seperti terlihat pada gambar tampilan di bawah ini :

a. Halaman website. Halaman utama website adalah halaman depan setelah login, ketika mengakses domain http://kompetensi.stikom-alkhairiyah.ac.id

\begin{tabular}{|c|c|c|c|}
\hline Aktor Utama & \multicolumn{3}{|l|}{ Dosen } \\
\hline $\begin{array}{l}\text { Aktor } \\
\text { Sekunder }\end{array}$ & \multicolumn{3}{|l|}{ - } \\
\hline Pemicu & \multicolumn{3}{|c|}{$\begin{array}{l}\text { Dosen mengakses alamat URL dan } \\
\text { memilih menu matakuliah }\end{array}$} \\
\hline Alur Utama & Langkah & Aktor & Sistem \\
\hline & 1 & Login & $\begin{array}{l}\text { Membuka } \\
\text { Menu }\end{array}$ \\
\hline & 2 & $\begin{array}{l}\text { Memilih } \\
\text { menu } \\
\text { kompetensi }\end{array}$ & $\begin{array}{l}\text { Menampilk } \\
\text { an menu } \\
\text { kompetensi }\end{array}$ \\
\hline
\end{tabular}

TABEL 5 FLOW OF EVENT MANAGED

\begin{tabular}{|l|l|}
\hline $\begin{array}{l}\text { Nama of Use } \\
\text { Case }\end{array}$ & Akses Kelola Matakuliah \\
\hline
\end{tabular}

b. Halaman pencarian. Ketika mahasiswa mengklik menu matakuliah akan menemukan pilih matakuliah sebagai berikut :

Gambar 2. Tampilan Halaman Website

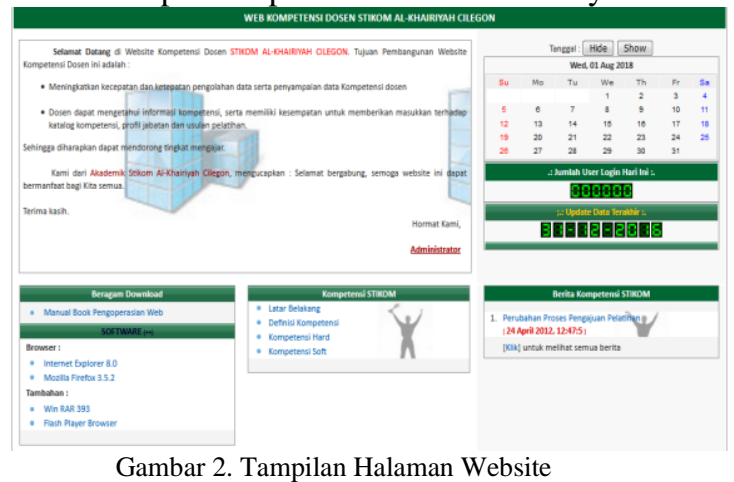




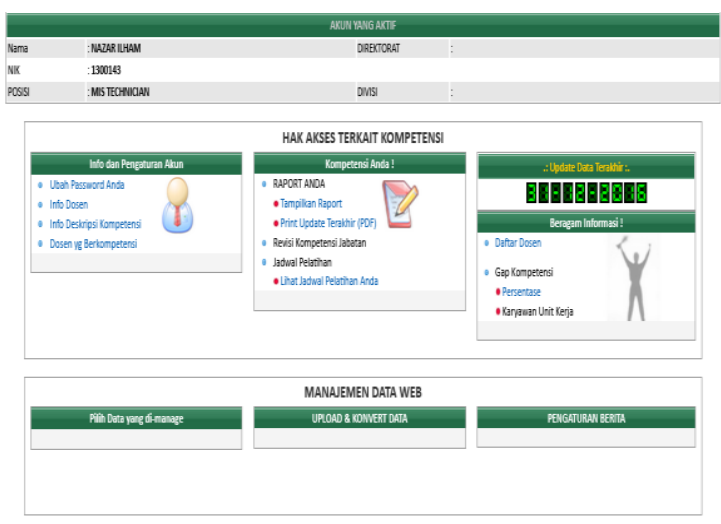

Gambar 3. Tampilan Halaman Menu Dosen

c. Halaman Login. Halaman admin hanya bisa di akses setelah melakukan login berkiut tampilan login admin :

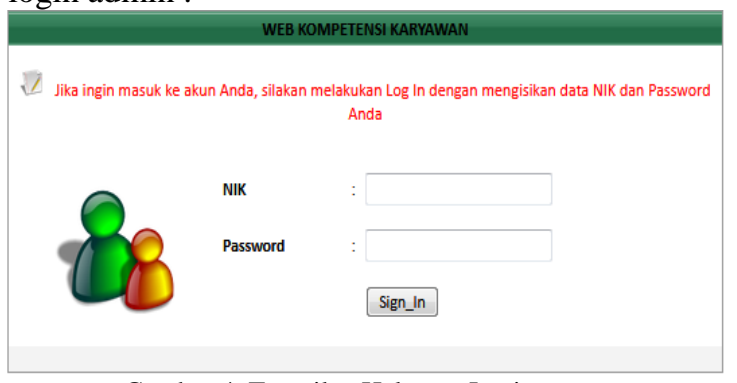

Gambar 4. Tampilan Halaman Login

d. Halaman Beranda admin. Tampilan Beranda Admin :

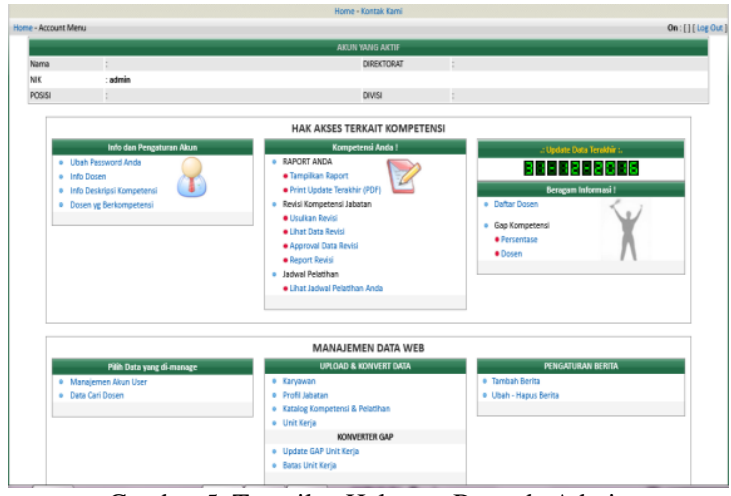

Gambar 5. Tampilan Halaman Beranda Admin

e. Form input dosen yang berkompetensi berfungsi untuk melihat dosen berkompetensi :

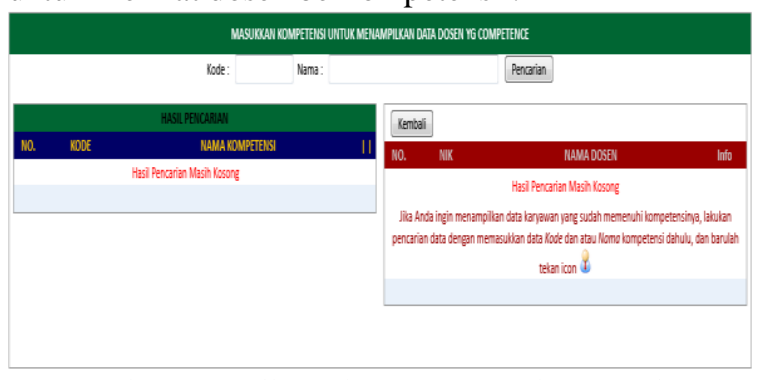

Gambar 6. Tampilan Halaman Dosen Berkompetensi dosen yang berkompetensi :

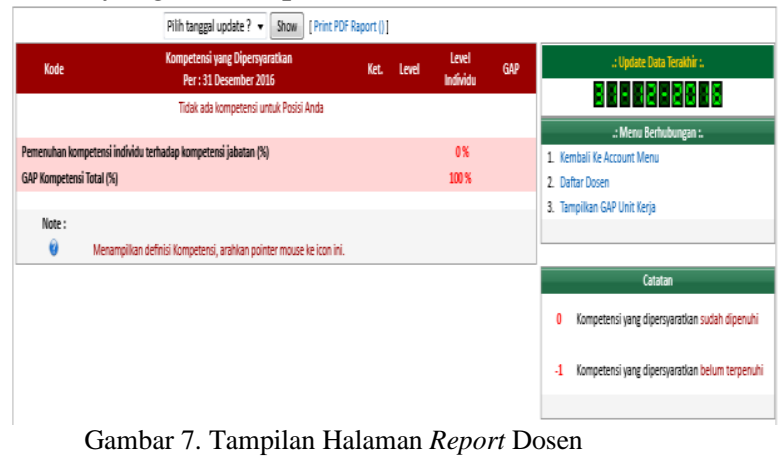

\section{SIMPULAN}

Dari hasil pembahasan uraian diatas maka dapat ditarik simpulan sebagai berikut :

Dengan adanya sistem informasi Kompetensi pada sekolah tinggi ilmu komputer $\mathrm{Al}$ - Khairiyah Cilegon dapat menunjang aktifitas Kompetensi. Baik untuk mencari dosen yang berkompetensi dan report dosen dan lainnya, oleh karena itu. Pengembangan perancangan antar muka aplikasi sistem E-Learning pada seluruh mata kuliah dengan menggunakan program hypertext prepocessor (PHP) dalam rangka meningkatkan mutu terhadap kinerja dan hasil pembelajaran.

\section{DAFTAR PUSTAKA}

1. Budi Djatmiko. (2004). Pengaruh Komitmen, Kepuasan Kerja, Kompetensi dosen terhadap Kepuasan dan Loyalitas Mahasiswa serta dampak terhadap Pangsa Pasar. Bandung: Disertasi Pascasarjana UNPAD.

2. Jogiyanto. (2005). Analisis dan Desain Siste Informasi. Yogyakarta: Andi.

3. Mulyasa, (2007). Standar Kompetensi dan Sertifikasi Guru. Cetakan 2. Bandung : Penerbit PT. Remaja Rosdakarya.

4. Oetomo, Budi Sutedjo Dharma (2002). Perencanaan \& Pembangunan Sistem Informasi. Yogyakarta: Andi.

5. Rusman, Dr, (2010) Seri Manajemen sekola bermutu model - model pembelajaran mengembangakan profesionalisme, PT Raja Grafindo Persada, Jakarata.

6. Seels Barbara B, (1994) Teknologi Pembelajaran Definisi dan Kawasanya Unit Percetakan Universitas Negeri Jakarta, Jakarata.

7. Widodo Prabowo Pudjo dan Herlawati, (2010) Menggunakan UML, PT Informatika, Bandung.

8. Zachman, J.A, (2008) John Zachman's Concise Definition of The Zachman Fremawork, Zachman CEO Internasional, Inc, USA.

9. Seels Barbara B, (1994) Teknologi Pembelajaran Definisi dan Kawasanya Unit Percetakan Universitas Negeri Jakarta, Jakarata.

10. https://moodle.org/

f. Form input report dosen untuk melihat hasil report 